\section{Research Square}

Preprints are preliminary reports that have not undergone peer review.

They should not be considered conclusive, used to inform clinical practice, or referenced by the media as validated information.

\title{
Covid-19 and low molecular weight heparin therapy: retrospective study of 257 patients.
}

Marco Stabile ( $\square$ marcostabile@gmail.com )

Castel San Giovanni Hospital, ASL PC, Italy https://orcid.org/0000-0001-6168-2605

Daniela Aschieri

Castel San Giovanni Hospital, ASL PC, Italy

Cristina Maestri

Castel San Giovanni Hospital, ASL PC, Italy

\section{Luca Rosato}

Castel San Giovanni Hospital, ASL PC, Italy

\section{Paola Novara}

Castel San Giovanni Hospital, ASL PC, Italy

Gianluca Lanati

Castel San Giovanni Hospital, ASL PC, Italy

Mariateresa Di Dio

Castel San Giovanni Hospital, ASL PC, Italy

Cosimo Franco

Castel San Giovanni Hospital, ASL PC, Italy

Giuseppina Bisceglie

Castel San Giovanni Hospital, ASL PC, Italy

Giuseppe Leddi

Castel San Giovanni Hospital, ASL PC, Italy

\section{Enrico fabrizi}

Catholic University Piacenza , Italy

\section{Paola Rucci}

Alma Mater Studiorum University, Bologna, Italy

Gloria Taliani

Sapienza University Roma, Italy

\section{Short Report}

Keywords: COVID-19, Heparin, Pneumonia, Thrombosis, Antithrombotic Therapy, Mortality

Posted Date: September 8th, 2020 
DOI: https://doi.org/10.21203/rs.3.rs-57730/v2

License: (c) (1) This work is licensed under a Creative Commons Attribution 4.0 International License. Read Full License 


\section{Abstract}

A hypercoagulability state with fatal thrombosis events seems to characterize the clinical worsening of COVID-19 pneumonia. The benefit and safety of anticoagulant doses of low molecular weight heparin (LMWH) in COVID-19 are still unknown. We evaluated in a retrospective cohort study 257 COVID-19 patients consecutively admitted to our COVID-Hospital from February 29, to April 7, 2020. We compared the in-hospital mortality between patients treated with prophylactic or therapeutic doses of LMWH.

Of the 257 patients enrolled, 49 (19.1\%) died during the hospitalization. Hospital mortality was significantly lower in patients treated with therapeutic doses of LMWH (enoxaparin 70-100 I.U./kg twice daily) $(17 / 126,13.5 \%)$, than in patients treated with prophylactic doses (60-90 I.U./kg once daily) $\left(32 / 131,24.4 \% ; \chi^{2}=4.98, p=0.02\right)$. In a stratified analysis by ventilation type, the only subgroup of patients who benefited from therapeutic LMWH was that requiring noninvasive mechanical ventilation $(\mathrm{OR}=0.099,95 \% \mathrm{Cl} 0.028-0.354, \mathrm{p}<0.001)$. No fatal bleedings were observed. In this retrospective study the treatment with therapeutic LMWH is safe and seems to reduce mortality in COVID-19 patients, especially among those who need noninvasive mechanical ventilation.

Authors Daniela Aschieri and Marco Stabile contributed equally to this work.

\section{Introduction}

The coronavirus SARS-CoV-2 infected thousands of people in Wuhan in December 2019 and spread rapidly worldwide coming to Italy with Codogno "case 1" on February 21, 2020. Since February 29, 2020, Castel San Giovanni Hospital was entirely dedicated to the treatment of coronavirus disease 2019 (COVID-19) patients. No specific pharmacological protocols with proved efficacy were, and actually are, available for the treatment of COVID-19 pneumonia patients ${ }^{1}$. Pneumonia with respiratory failure is the main clinical feature of COVID-19 and it is often associated with systemic inflammation that induces diffuse endothelial injury and hypercoagulability state ${ }^{2,3,4}$. The relationship between viral infections and thrombosis is well recognized, but seems to be predominant in SARS-CoV2 infection leading to lifethreatening thrombotic complications and worsening ${ }^{5}$. Low molecular weight heparin (LMWH) is recommended in COVID-19 patients by some expert consensus but its efficacy and safety at therapeutic doses has not yet been described ${ }^{6}$. We assumed that low molecular weight heparin at therapeutic doses could exert a beneficial effect on clinical course of COVID-19 taking advantage of its anticoagulant, antiinflammatory and in vitro antiviral properties $7,8,9,10,11,12$. The aim of this study was to evaluate the inhospital mortality of COVID-19 patients treated with LMWH administered at prophylactic or+ therapeutic doses.

\section{Results}

Between February $29^{\text {th }}$ and April $7^{\text {th }}, 2020,351$ patients were admitted to the Castel San Giovanni COVID Hospital. Ninety-four patients were excluded from the analysis for the following reasons: 30 were 
discharged, 43 died and 17 were transferred to other care units ( 7 to Intensive Care Units outside our province) within 7 days. Three were not COVID-19 confirmed patients and 1 patient was undergoing hemodialysis (Fig. 1). The characteristics of the 257 patients included in the analyses are shown in Table 1.

One hundred thirty-one (51\%) received prophylactic LMWH ( 60-90 I. U. / kg daily for at least 7 days) and 126 patients (49\%) received therapeutic LMWH (70-100 I. U. / $\mathrm{kg}$ twice daily for at least 7 days) treatment.

Two hundred-thirty-two patients (90.3\%) received empiric antibiotic treatment (azithromycin $500 \mathrm{mg} /$ day for at least 5 days), 237 patients (92.2\%) received hydroxychloroquine (200 mg twice a day for at least 5 days), 146 patients (55.7\%) received corticosteroids (methylprednisolone $1 \mathrm{mg} / \mathrm{Kg}$ twice a day i.v. or dexamethasone $40 \mathrm{mg}$ i.v. once a day for 3 days followed by decreasing dosage), 236 patients $(91.8 \%)$ received anti-retroviral therapy (darunavir/cobicistat $800+150 \mathrm{mg}, 1$ tablet for 7 days and/or lopinavir/ritonavir $200+50 \mathrm{mg}, 1$ tablet twice a day for 7 days). Twenty-five patients (9.5\%) were eligible for treatment with tocilizumab ( $8 \mathrm{mg} / \mathrm{kg}$ i.v. in a single or double dose). D-dimer was collected in 93 patients, and the mean peak level was $5241 \mu \mathrm{g} / \mathrm{ml}$; the median level was $1489 \mu \mathrm{g} / \mathrm{ml}$.

All patients required oxygen therapy: 135 patients (52,5\%) needed nasal cannulas with oxygen flow $\leq 6$ I/min or non-rebreather mask with oxygen flow from 10 to $15 \mathrm{l} / \mathrm{min}$ (Vent 1 ); 67 patients $(26.1 \%$ ) required non-invasive mechanical ventilation (Vent 2) and 55 patients (21.4\%) required invasive mechanical ventilation (Vent 3).

Patients treated with prophylactic and therapeutic LMWH had similar demographic and clinical characteristics (Table 1). However, patients in the therapeutic LMWH group more frequently received corticosteroids, hydroxychloroquine and tocilizumab.

\section{Hospital mortality in patients treated with therapeutic $L M W H$ vs. prophylactic $L M W H$}

During hospitalization, 49 patients died (49/257, 19.1\%). Hospital mortality was significantly lower in patients treated with therapeutic $L M W H(17 / 126,13.5 \%)$ than in those treated with prophylactic $L M W H$ $\left(32 / 131,24.4 \% ; \chi^{2}=4.98, p=0.02\right)$. The crude odds ratio of mortality in patients treated with therapeutic $L M W H$ was $O R=0.483,95 \% \mathrm{Cl} 0.252-0.923, p<0.05$.

When analyses were stratified by type of ventilation, patients with noninvasive mechanical ventilation (Vent-2) were those who mostly benefited from therapeutic doses of $L M W H$, since in these patients, the mortality was lower than in those treated with prophylactic $L M W H(O R=0.099,95 \% \mathrm{Cl} 0.028-0.354$, $p<0.001)$. In patients that required the other two types of ventilation, no significant differences in mortality rate were observed (Vent1: $O R=0.853,95 \% \mathrm{Cl} 0.309-2.355, p=0.759$; Vent 3: $O R=0.792,95 \%$ $\mathrm{Cl} 0.220-2.852, p=0.721)$. Multivariable linear regression was conducted to determine whether 
therapeutic $L M W H$ was more effective than prophylactic $L M W H$ in reducing in-hospital mortality after controlling for concomitant administration of corticosteroids, hydroxychloroquine and tocilizumab. The results indicate a significant $62.6 \%$ reduction in the mortality risk among those treated with therapeutic LMWH (OR $=0.374,95 \% \mathrm{Cl} 0.177-0.792, p=0.01)$ (Table 2).

Moreover, Cox regression analysis was conducted to analyse the risk of in-hospital mortality after controlling for concomitant administration of corticosteroids, tocilizumab and hydroxycloroquine. The results indicate a significant $70.9 \%$ reduction in the mortality risk among those treated with T-LMWH (HR $=0.291,95 \% \mathrm{Cl} 0.153-0.556$ ) (Table 3 and fig. 2).

\section{Safety of therapeutic LMWH}

Two major and 1 minor bleeding episode were recorded in therapeutic LMWH patients (3/126; $2.4 \%)$ : two patients had psoas muscle hematoma that required two packed red blood cells transfusion each and one patient had gluteus muscle hematoma that recovered spontaneously. No patient needed invasive treatment.

\section{Discussion}

In this retrospective study, therapeutic LMWH appears to be the only one treatment associated with a significant reduction in mortality. Very few data exist on the relationship between therapeutic doses of $L M W H$ and the reduction of mortality rate in COVID-19 patients. In a recent retrospective study, Tang et al. treated COVID-19 patients with therapeutic doses of heparin, reporting a low mortality rate at 28 days' follow-up only in a subgroup of patients with SIC score $\geq 4$ and D-dimer test $>6$-fold the upper limit ${ }^{13}$. During the first two weeks of our involvement in this emergency setting, D-dimer test was not systematically recorded in all patients, and no analysis could be carried out comparing this predictive parameter apart from a few patients. In our study, patients who mostly benefited from therapeutic doses of $L M W H$ were those included in the Vent-2 group, who needed noninvasive mechanical ventilation with helmet $C$-PAP $(p<0.001)$. We can speculate that in this specific clinical setting, the hypercoagulability state, which worsens the respiratory clinical picture, can benefit from the administration of therapeutic doses of LMWH.

Conversely, in the mechanically ventilated patient group (Vent-3), a prognostic advantage from LMWH administered at therapeutic doses was not found, probably because in intensive care unit (ICU) patients, the disease is too advanced to benefit from the anti-inflammatory and anticoagulant activity of $L M W H$. Our findings are consistent with a recent retrospective analysis of 150 COVID-19 ICU patients, in which a significantly high thromboembolic event rate was also found in those treated with anticoagulant therapy

14. Most likely, in such an advanced state of the disease, even a therapeutic dose of heparin may not improve the outcome ${ }^{15}$. 
SARS-Cov-2 infection induces diffuse endothelial inflammatory status due to direct viral infection of endothelial cells in different organs of the human body ${ }^{16}$. Endothelial damage is the main determinant of microvascular dysfunction that leads to vasoconstriction and subsequent organ ischemia, inflammation, tissue edema and a procoagulant state ${ }^{17}$. The hypercoagulability state has been demonstrated in other viral infections ${ }^{18,19}$. During the epidemic SARS-COV-2, vascular endothelial damage in both small and mid-sized pulmonary vessels was observed and resulted in pulmonary infarction ${ }^{20,21}$. In COVID-19 patients, the radiological features observed on CT angiography images suggest venous and arterial thrombosis ${ }^{22}$, and diffuse thrombosis of the peripheral small vessels has also been found in autopsy studies ${ }^{23}$. Therefore, the protective effect of therapeutic doses of LMWH is probably due to the prevention/treatment of such thrombotic events, which is in keeping with the benefit of anticoagulation in a particular subset of patients with severe pulmonary involvement.

Apart from its anticoagulant properties, $L M W H$ has an anti-inflammatory effect that reduces the uncontrolled activation of the cytokine cascade by inhibiting the release of $I L-6{ }^{24}$. High serum IL-6 levels are observed in the advanced stages of COVID-19, significantly and directly correlate with the severity of the disease $25,26,27$.

Lastly, no fatal bleedings occurred in this study population, which indicates that the treatment with therapeutic doses of LMWH can be considered safe ${ }^{28}$.

Limitations in the current study include the potential selection bias and residual confounding associated with a small sample size. It is also possible that improving the learning curve in noninvasive ventilation may have produced a nonpharmacological benefit in the management of patients over time. However, our observation may be useful to stimulate prospective studies to evaluate which heparin dose could be optimal in the treatment of Covid-19 patients. Future randomized clinical trials are still needed to confirm this observation that could change the pharmacological treatment of this life-threatening disease.

\section{Methods}

Adult patients consecutively admitted to Castel San Giovanni Hospital from February 29 to April 7, 2020 with confirmed COVID-19 pneumonia were included in the study.

The diagnosis was consistent with the World Health Organization interim guidelines and was confirmed by RNA detection of the SARSCOV-2 from oropharyngeal and nasopharyngeal swab sample ${ }^{29}$. In all patients Computed Tomography scan diagnosis of pulmonary pneumonia was performed. We excluded from the analysis patients on hemodialysis and patients with a hospital stay $\leq 7$ days to exclude either mild forms of disease with an early discharge or more advanced forms of disease with early death or early transfer to another hospital for whom heparin treatment would not be evaluated ${ }^{30}$.

The therapeutic approach included hydroxychloroquine, azithromycin, anti-viral therapy (lopinavir/ritonavir and/or darunavir/cobicistat), corticosteroid, tocilizumab (in selected patients) and 
LMWH. LMWH was administered at a prophylacticdose corresponding to 60-90 I. U. once daily (prophylaxis of DVT/EP in patients bedridden) for at least 7 days, or at therapeutic dose corresponding to 70-100 I. U./ kg twice daily, for at least 7 days ${ }^{31}$. The decision to prescribe prophylactic LMWH or therapeutic LMWH was left to the medical team caring for each patient. Patients with a HAS BLED score $\geq 3$ were excluded from therapeutic $L M W H$ treatment ${ }^{32}$. The approval of the Healthcare Directorate of Piacenza Local Health Authority was obtained and granted a waiver of informed consent.

\section{Data Collection}

Data were extracted from electronic medical records and included age, gender, clinical characteristics, inhospital pharmacological treatments and type of oxygenation/ventilation needed. The comorbidities most recorded were arterial hypertension, diabetes mellitus, cardiovascular diseases (defined as history of myocardial infarction, ischemic stroke, and peripheral atheromasia), atrial fibrillation, chronic obstructive pulmonary disease, chronic kidney disease (Cockroft-Gault e-GFR< $60 \mathrm{ml} / \mathrm{min} / 1.73 \mathrm{~m}^{2}$ ) and the presence of active or previous cancer. Bleeding events were also recorded and classified according to the International Society of Thrombosis and Hemostasis (ISTH) definition of bleeding ${ }^{33}$. Patients were followed up until discharge or death until April 20, 2020, whichever came first.

\section{End points}

The primary endpoint of the study was in-hospital mortality and the secondary endpoint was safety.

\section{Statistical analysis}

Patients treated with prophylactic $L M W H$ and therapeutic $L M W H$ were compared on continuous variables using the t-test and on categorical variables using the $\chi^{2}$-test. Crude odds ratios of hospital mortality therapeutic LMWH were obtained using univariate logistic regression analysis. In order to control for the different proportion of patients receiving concomitant treatments in the two groups, adjusted odds ratios were estimated using multivariable logistic regression. Moreover, Cox regression analysis was used to compare the mortality risk of the two treatment groups, adjusted for concomitant treatment. Data were censored at death or date of discharge until April 20, 2020.

All statistical analyses were performed using IBM SPSS, version $25^{34}$. All eligible patients were enrolled for the study, thereby the sample size was not chosen using statistical criteria. Nonetheless, we determined that a sample size of $n=257$ would be sufficient to detect a $10 \%$ difference in mortality between the two study groups using a chi-square test, with alpha $=0.05$, power $=0.80$, and equal sized groups. The adequacy of the sample size was confirmed by our results. 


\section{Declarations}

Funding No specific funding has supported this study.

Conflicts of interest/Competing interests The authors have no conflicts of interest to declare in relation to the present work.

Ethics approval The Healthcare Directorate of Piacenza Local Health Authority approved the therapeutic protocol.

Consent to participate The Healthcare Directorate of Piacenza Local Health Authority granted a waiver of informed consent.

Consent for publication No consent for publication was requested, because data are presented in aggregate form and do not include sensitive data.

Availability of data and material Data are available upon request from the first author.

Code availability A commercial software, IBM SPSS version 25.0, was used for the data analysis.

Authors' contributions M. S., D. A. contributed to the design and implementation of the research, E. F. and P. R. to the statistical analysis of the results. M. S., D. A., C. M., L. R., P. N. and G. L. contributed to the writing of the first draft of manuscript. G. T. contributed to the writing and the interpretation of the results. All authors provided important intellectual contents and approved the final version of the manuscript and agreed to the publication of the manuscript.

Acknowledgement Special thanks to the members of Castel San Giovanni Corona-Speciality Hospital:Francesco Andrani, Angelo Benedetti, Mara Bozzarelli, Carlo Cagnoni, Paolo Cambrini, Esther Centenara, Sara Chiesa, Mauro Codeluppi, Patrizia Colazzo, Donatella Covini, Angelo Mangia, Demostene Marifoglou, Massimiliano Mazzilli, Samantha Mazzocchi, Monica Pellegrini, lacopo Pellegrino, Annamaria Pieri, Daria Sacchini, Tiziana Spezzano, Corrado Tosca, Lucia Torretta, Gioacchino Valenti, Ercole Zanotti.

\section{References}

1. Kalil AC Treating COVID-19-Off-Label Drug Use, Compassionate Use, and Randomized Clinical Trials During Pandemics. JAMA;32 3(19):1897-1898. doi:10.1001/jama.2020.4742 (2020)

2. Chen N, Zhou M, Dong $X$ et al. Epidemiological and clinical characteristics of cases of 2019 novel coronavirus pneumonia in Wuhan: a descriptive study. Lancet 395:207-513 (2020)

3. Huag C, Wang Y, Li X et al. Clinical features of patients infected with 2019 novelcoronavirus in Wuhan, China. Lancet 395:497-506 (2020)

4. Tang N, Li D, Wang X, Sun Z. Abnormal coagulation parameters are associated with poor prognosis in patients with novel coronavirus pneumonia. J Thromb Haemost. ;18(4):844-847 
https://doi.org/10.1111/jth.14768 (2020)

5. Helms J, Tacquard C, Saverac $F$ et al. High risk of thrombosis in patients with severevSARS-CoV-2 infection: a multicenter prospective cohort study. Intensive Care Med.;46(6):1089-1098. doi:10.1007/s00134-020-06062-x (2020)

6. World Health Organization. Coronavirus Disease 2019 (COVID-19). Clinical management of severe acute respiratory infection (SARI) when COVID-19 disease is suspected. (2020).

7. Hao C, Sun M, Wang H, Zhang L et al. Low Molecular Weight Heparins and Their Clinical Applications. Prog Mol Biol Trans/ Sci163:21-39 (2019)

8. Hirsh J, Warkentin TE, Shaughnessy SG, et al. Heparin and low molecular weight heparin: mechanism of action, pharmacokinetics, dosing, monitoring, efficacy and safety. Chest. 119 (1 Suppl): 64S-95S (2001)

9. Mousavi S, Moradi M, Khorshidahmad T, Motamedi M. Anti-Inflammatory Effects of Heparin and Its Derivatives: A Systematic Review. Adv Pharmacol Sci.;2015:507151. doi:10.1155/2015/507151 (2015)

10. Lin L, Lu L, Cao W, Li T. Hypothesis for potential pathogenesis of SARS-CoV-2 infection-a review of immune changes in patients with viral pneumonia. Emerg Microbes Infec; 9: 727-732 (2020)

11. Johnson Z, Kosco-Vilbois MH, Herren S, et al. Interference with heparin binding and oligomerization creates a novel anti-inflammatory strategy targeting the chemokine system. J Immunol.;173(9):57765785. doi:10.4049/jimmunol.173.9.5776 (2004)

12. Thachil J. The versatile heparin in COVID-19. J Thromb Haemost.;18(5):1020-1022. doi:10.1111/jth. 14821 (2020)

13. Tang N, Bay H, Chen $X$ et al. Anticoagulant treatment is associated with decreased mortality in severe coronavirus disease 2019 patients with coagulopathy. J Thromb Haemost 18(5):1094-1099. doi: 10.1111/jth.14817 (2020)

14. Helms J, Tacquard C, Severac F et al. High risk of thrombosis in patients in severe SARS-CoV-2 infection: a multicenter prospective cohort study. Intensive Care Med. 10.1007/s00134-020-06062-x (2020)

15. Llitjos JF, Leclerc M, Chochois $C$ et al. High incidence of venous thromboembolic events in anticoagulated severe COVID-19 patients. Intensive Care Med https://doi.org/10.1007/s00134-02006082-7 (2020)

16. Varga Z, Flammer AJ, Steiger $P$ et al. Endothelial cell infection and endotheliitis in COVID-19. Lancet 395(10234): 1417-1418 (2020)

17. Bonetti PO, Lerman LO, Lerman A. Endothelial dysfunction - a marker of atherosclerotic risk. Arterioscl Thromb Vas 23:168-75 (2003)

18. Antoniak S. The coagulation system in host defense. Res Pract Thromb Haemost 2(3):549-57 (2018) 
19. Antoniak S, Mackman N. Multiple roles of the coagulation protease cascade during virus infection. Blood 123(17):2605-13 (2014)

20. Hwang, D, Chamberlain D, Poutanen S et al. Pulmonary pathology of severe acute respiratory syndrome in Toronto. Mod Pathol 18, 1-10 . https://doi.org/10.1038/modpathol.3800247 (2005)

21. Lax SF, Skok K, Zechner P, et al. Pulmonary Arterial Thrombosis in COVID-19 With Fatal Outcome: Results From a Prospective, Single-Center, Clinicopathologic Case Series [published online ahead of print, 2020 May 14]. Ann Intern Med. 2020;M20-2566. doi:10.7326/M20-2566 (2020)

22. Casey K, Iteen A, Nicolini $R$ et al. COVID-19 pneumonia with hemoptysis: Acute segmental pulmonary emboli associated with novel coronavirus infection. Am J Emerg Med S0735-6757(20)30239-4. doi:10.1016/j.ajem.2020.04.011 (2020)

23. Wichmann D, Sperhake J, Lutgehetmann M et al. Autopsy Findings and Venous Thromboembolism in patients with COVID-19: A Prospective Cohort Study. Ann Intern Med doi:10.7326/M20-2003 (2020)

24. Shastri MD, Stewart N, Horne J et al. In-vitro suppression of IL-6 and IL-8 release from human pulmonary epithelial cells by non-anticoagulant fraction of enoxaparin. PLoS One. 11;10(5):e0126763. doi: 10.1371/journal.pone.0126763. (2015)

25. Pons S, Fodil S, Azoulay E, Zafrani L. The vascular endothelium: the cornerstone of organ dysfunction in severe SARS-CoV-2 infection. Crit Care.,24(1):353. doi:10.1186/s13054-020-03062-7 (2020)

26. Guang Chen, Di Wu, Wei Guo et al. Clinical and immunological features of severe and moderate coronavirus disease 2019. J.Clin. Invest 130(5):2620-2629 (2020)

27. Xu X, Han M, Li T, Sun W et al. Effective treatment of severe COVID-19 patients with tocilizumab. Proc Natl Acad Sci U S A. Apr 29. doi: 10.1073/pnas.2005615117 (2020)

28. Cossette B, Pelletier ME, Carrier $N$ et al. Evaluation of bleeding risk in patients exposed to therapeutic unfractionated or low-molecular-weight heparin: a cohort study in the context of a quality improvement initiative. Ann Pharmacother 2010; 44(6):994-1002. doi: 10.1345/aph.1M615 (2010)

29. World Health Organization. Clinical management of severe acute respiratory infection when novel coronavirus (2019-nCoV) infection is suspected: interim guidance . (2020) WHO/2019nCoV/clinical/2020.5 Available at: https://www.who.int/docs/default-source/coronaviruse/clinicalmanagement-of-novel-cov.pdf

30. Turpie AG, Chin BS, Lip GY. Venous thromboembolism: pathophysiology, clinical features, and prevention. BMJ.;325(7369):887-890. doi:10.1136/bmj.325.7369.887 (2002)

31. Schünemann HJ, Cushman M, Burnett AE, et al. American Society of Hematology 2018 guidelines for management of venous thromboembolism: prophylaxis for hospitalized and non hospitalized medical patients. Blood Adv.;2(22):3198-3225. doi:10.1182/bloodadvances.2018022954 (2018)

32. Lip GY, Frison L, Halperin JL, Lane DA. Comparative validation of a novel risk score for predicting bleeding risk in anticoagulated patients with atrial fibrillation: the HAS-BLED (Hypertension, Abnormal 
Renal/Liver Function, Stroke, Bleeding History or Predisposition, Labile INR, Elderly, Drugs/Alcohol Concomitantly) score. J Am Coll Cardiol;57(2):173-180. doi:10.1016/j.jacc.2010.09.024 (2011)

33. Kaatz $S$, Ahmad D, Spyropoulos AC et al. Definition of clinically relevant non-major bleeding in studies of anticoagulants in atrial fibrillation and venous thromboembolic disease in non-surgical patients: communication from the SSC of the ISTH. J Thromb Haemost 13:2119-21 (2015) IBM Corp. Released 2017. IBM SPSS Statistics for Windows, Version 25.0. Armonk, NY: IBM Corp.

\section{Tables}

Table 1. Demographic, clinical characteristics and treatment of the study population and comparisons between patients treated with P-LMWH $(N=131)$ and $T-L M W H(N=126)$. 


\begin{tabular}{|c|c|c|c|c|}
\hline & Overall sample & $P-L M W H$ & $T-L M W H$ & $p$-value \\
\hline Variables & $\begin{array}{c}\text { Mean } \pm S D \text { or } \\
N(\%)\end{array}$ & $\begin{array}{c}\text { Mean } \pm S D \text { or } \\
N(\%)\end{array}$ & $\begin{array}{c}\text { Mean } \pm S D \text { or } \\
N(\%)\end{array}$ & \\
\hline Age (years) & $69.3 \pm 10.7$ & $69.4(11.9)$ & $69.2(9.5)$ & $0.836^{\circ}$ \\
\hline Gender & & & & $0.583^{\wedge}$ \\
\hline Male & $174(67.7 \%)$ & $91(69.5 \%)$ & $83(65.9 \%)$ & \\
\hline Female & $83(32.3 \%)$ & $40(30.5 \%)$ & $43(34.1 \%)$ & \\
\hline Arterial hypertension & $162(63.0 \%)$ & $83(63.4 \%)$ & $79(62.7 \%)$ & $0.913^{\wedge}$ \\
\hline Diabetes mellitus type 2 & $46(17.9 \%)$ & $25(19.1 \%)$ & $21(16.7 \%)$ & $0.613^{\wedge}$ \\
\hline Cardiovascular disease & $44(17.1 \%)$ & $28(21.4 \%)$ & $16(12.7 \%)$ & $0.065^{\wedge}$ \\
\hline Dyslipidaemia & $37(14.4 \%)$ & $19(15.0 \%)$ & $18(14.3 \%)$ & $0.879^{\wedge}$ \\
\hline Obesity & $25(9.7 \%)$ & $12(9.2 \%)$ & $13(10.3 \%)$ & $0.754^{\wedge}$ \\
\hline Smoke & $21(8.2 \%)$ & $12(9.4 \%)$ & $9(7.1 \%)$ & $0.518^{\wedge}$ \\
\hline Chronic or paroxysmal atrial fibrillation & $33(12.8 \%)$ & $17(13.0 \%)$ & $16(12.8 \%)$ & $0.966^{\wedge}$ \\
\hline Chronic obstructive pulmonary disease & $22(8.6 \%)$ & $13(9.9 \%)$ & $9(7.1 \%)$ & $0.426^{\wedge}$ \\
\hline Chronic kidney disease & $22(8.6 \%)$ & $14(10.8 \%)$ & $8(6.3 \%)$ & $0.207^{\wedge}$ \\
\hline History of cancer & $18(7.0 \%)$ & $11(8.4 \%)$ & $7(5.6 \%)$ & $0.372^{\wedge}$ \\
\hline \multicolumn{5}{|l|}{ IN-HOSPITAL TREATMENT } \\
\hline Azithromycin & $232(90.3 \%)$ & $108(82.4 \%)$ & $114(90.5 \%)$ & $0.061^{\wedge}$ \\
\hline Hydroxychloroquine & $237(92.2 \%)$ & $114(87.0 \%)$ & $123(97.6 \%)$ & $0.002^{\wedge}$ \\
\hline Corticosteroid & $146(56.8 \%)$ & $44(33.6 \%)$ & $102(81.0 \%)$ & $<0.001^{\wedge}$ \\
\hline \multicolumn{5}{|l|}{ Anti-viral therapy } \\
\hline $\begin{array}{l}\text { Lopinavir/ritonavir and/or } \\
\text { Darunavir/cobicistat }\end{array}$ & $236(91.8 \%)$ & $118(90.1 \%)$ & $119(94.4 \%)$ & $0.191^{\wedge}$ \\
\hline Tocilizumab & $25(9.7 \%)$ & $2(1.5 \%)$ & $23(18.3 \%)$ & $<0.001^{\wedge}$ \\
\hline Oxygen support & & & & $0.066^{\wedge}$ \\
\hline Vent 1 & $135(52.5 \%)$ & $78(59.5 \%)$ & $57(42.5 \%)$ & \\
\hline Vent 2 & $67(26.1 \%)$ & $28(21.4 \%)$ & $39(31.0 \%)$ & \\
\hline Vent 3 & $55(21.4 \%)$ & $25(19.1 \%)$ & $30(23.8 \%)$ & \\
\hline
\end{tabular}

P-LMWH = Low Molecular Weight Heparin at prophylactic doses 60-90 IU/kg once a day; T- LMWH = Low Molecular Weight Heparin at therapeutic doses 70-100 IU/kg twice a day. Vent 1: nasal cannula with oxygen flow < $6 \mathrm{I} / \mathrm{min}$ or non-rebreather mask with oxygen flow from 10 to $15 \mathrm{l} / \mathrm{min}$; Vent 2: non-invasive mechanical ventilation; Vent 3: invasive mechanical ventilation. ${ }^{\wedge}$ Chi-square test. ${ }^{\circ}$ t-test. 
Table 2. Odds ratio of mortality in patients treated with T- LMWH vs. P-LMWH, adjusted for concomitant drug intake. Results of multivariable logistic regression model.

\begin{tabular}{|c|c|c|c|c|c|c|}
\hline & \multirow[b]{2}{*}{$B$} & \multirow[b]{2}{*}{ S.E. } & \multirow[b]{2}{*}{$p$} & \multirow[b]{2}{*}{$O R$} & \multicolumn{2}{|c|}{ 95\% C.I.for OR } \\
\hline & & & & & Lower & Upper \\
\hline T-LMWH VS. P-LMWH & -0.983 & 0.382 & 0.010 & 0.374 & 0.177 & 0.792 \\
\hline Corticosteroids & 0.763 & 0.375 & 0.042 & 2.145 & 1.029 & 4.474 \\
\hline \begin{tabular}{|l|} 
Hydroxychloroquine \\
\end{tabular} & 0.074 & 0.603 & 0.902 & 1.077 & 0.330 & 3.513 \\
\hline Tocilizumab & -0.878 & 0.780 & 0.260 & 0.416 & 0.090 & 1.918 \\
\hline Constant & -1.470 & 0.574 & 0.010 & 0.230 & & \\
\hline
\end{tabular}

T- LMWH vs. P-LMWH

P-LMWH = Low Molecular Weight Heparin at prophylactic doses 60-90 IU/kg once a day; T- LMWH = LoW Molecular Weight Heparin at therapeutic doses 70-100 IU/kg twice a day.

Table 3. Hazard ratio of mortality in patients treated with T-LMWH vs. P-LMWH, adjusted for concomitant drug intake. Results of Cox regression model.

\begin{tabular}{lc|r|r|r|r|r} 
& & & & & \multicolumn{2}{|c}{$95,0 \%$ CI for HR } \\
& $B$ & $S E(B)$ & \multicolumn{1}{|c|}{$p$} & HR & Lower & Upper \\
\hline T- LMWH vs. P-LMWH & -1.233 & 0.330 & $<0.001$ & 0.291 & 0.153 & 0.556 \\
\hline Tocilizumab & -0.896 & 0.742 & 0.227 & 0.408 & 0.095 & 1.748 \\
\hline Corticosteroids & 0.142 & 0.321 & 0.657 & 1.153 & 0.615 & 2.161 \\
\hline Hydroxychloroquine & 0.129 & 0.533 & 0.808 & 1.138 & 0.401 & 3.233 \\
\hline
\end{tabular}

\section{Figures}


From February 29 to 7 April 2020

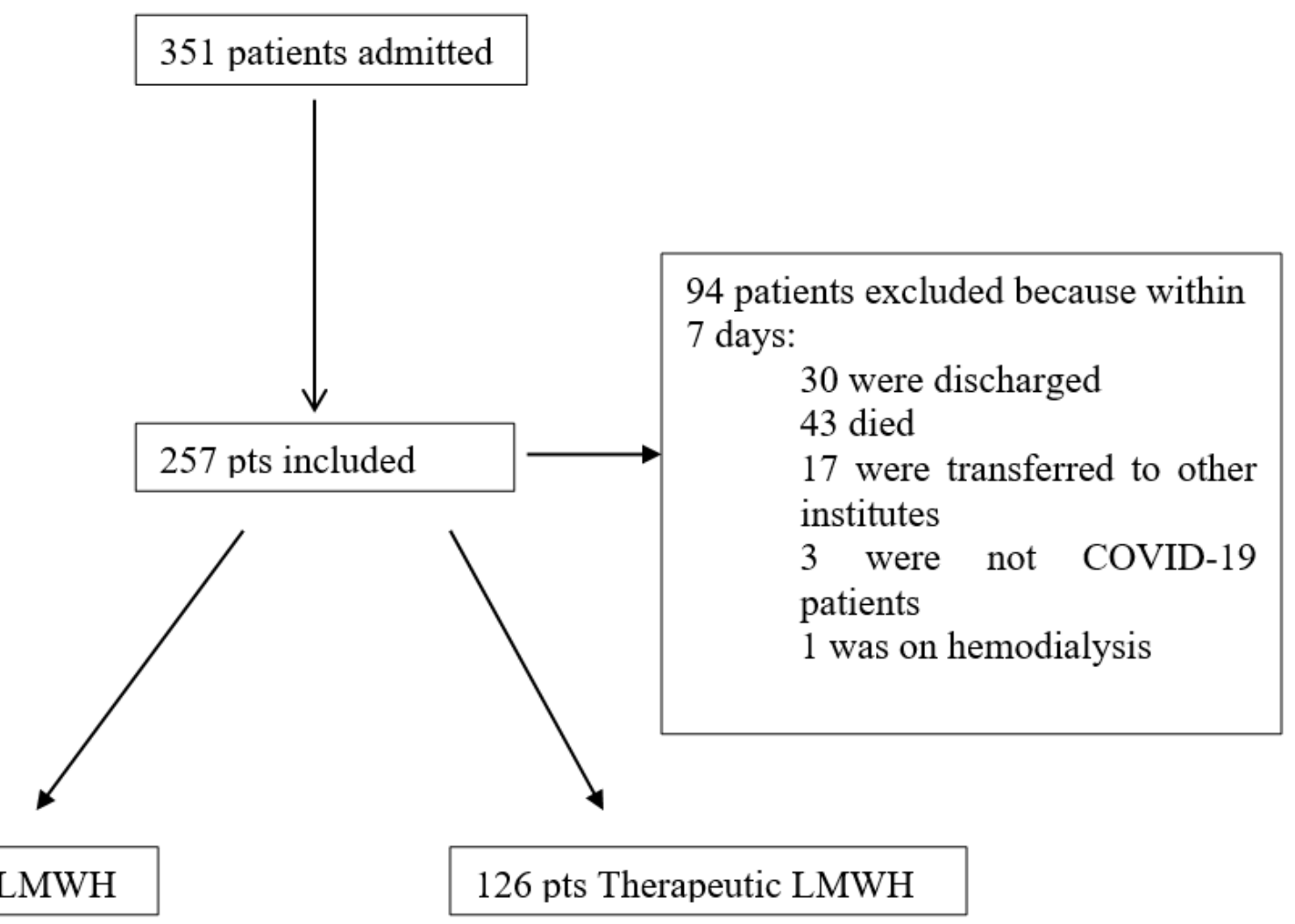

Figure 1

Study cohort: exclusion flow chart 


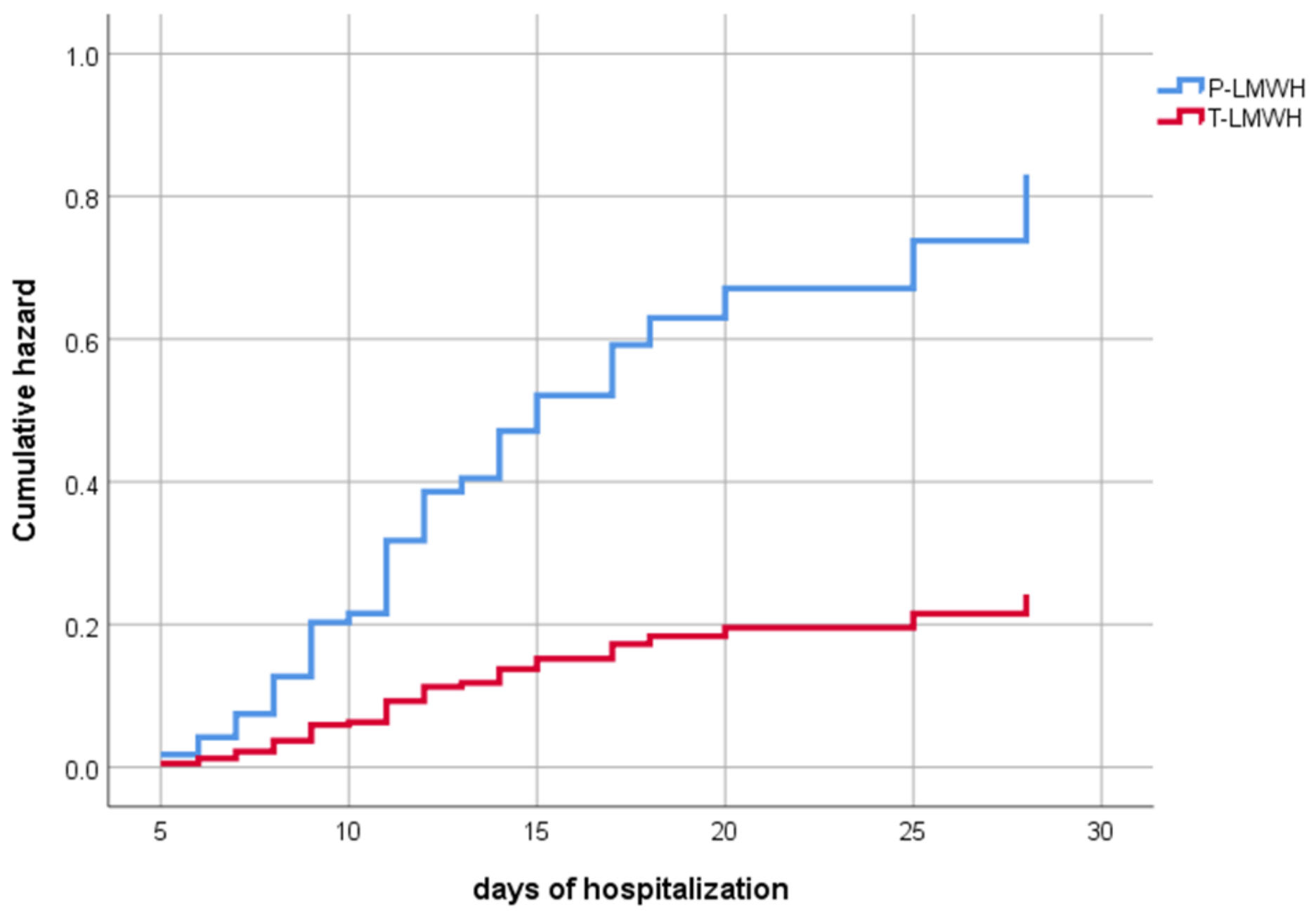

Figure 2

Hazard ratio in patients treated with T-LMWH vs P-LMWH adjusted for concomitant drug intake 